\title{
W sieci metafor
}

\section{Marek Kaźmierczak}

ORCID: 0000-0002-4913-2149
Miłosz Babecki, Metaforyka polskich gier przeglądarkowych. Konteksty - porównania - analizy (Olsztyn: Wydawnictwo Uniwersytetu Warmińsko-Mazurskiego w Olsztynie, 2020)

Zacznę od tego, że książka dra Miłosza Babeckiego jest ciekawa, cenna poznawczo, ważna. Innych badaczy zachęcam do lektury. Po takich słowach mógłbym zakończyć pisanie tej recenzji.

Każdy krytyczny czytelnik niemal natychmiast z nieufnością odniesie się do zdań wyrażonych powyżej, przynajmniej z powodu nacechowanych wartościująco etykiet. Recenzujący tę monografię pisze, że jest ona „ciekawa”. Wiemy jednak, że jest to przecież arbitralny sąd. Zapewne z tego powodu po przecinku autor recenzji dodał: „cenna poznawczo”. Tak. Cenna poznawczo, bo Babecki omówił - w ramach próby dostępnościowej - 46 gier przeglądarkowych traktowanych jako metafory wydarzeń politycznych, które miały miejsce w latach 2005-2013 w Polsce. Zawartość różnorodnych dyskursywnych egzemplifikacji (m.in. odniesienia do gier polskich, amerykańskich, do filmu) oraz połączenie licznych koncepcji badawczych (medioznawczych, literaturoznawczych, kulturoznawczych, socjologicznych, groznawczych) pokazują, że gry przeglądarkowe nie są przypadkowym „hybrydowym” zdigitalizowanym „felieto- 
nem", w ramach recenzowanej monografii quasi-politycznym, lecz ważnym narzędziem gier (sic!) politycznych i kulturowych, w które uwikłani są użytkownicy Internetu pełniący w życiu społecznym różne role. Recenzent napisał w pierwszym akapicie, że książka Metaforyka polskich gier przeglądarkowych jest „ważna” - ważna między innymi dla osób, które badają dyskurs publiczny w Polsce, komunikację międzyludzką, zajmują się tekstologią, Internetem, wreszcie grami, w tym grami cyfrowymi.

Gry przeglądarkowe uzmysławiają nam w sposób szczególny, na bieżąco, że życie publiczne w wymiarze mikro- i makrospołecznym wciąż się opiera na następującym schemacie: X gra z Y o COŚ. W ramach monografii Babeckiego powyższy schemat wpisujemy w realia Internetu: nawet jeśli $\mathrm{Y}$ nie wie o istnieniu $\mathrm{X}$, to jednak dynamika Sieci pozwala, aby $\mathrm{X}$ mógł w warstwie nie tylko metaforycznej i symbolicznej wziąć w nawias - bywa, że dezynwolturę, bywa, że obojętność, bywa, że arogancję Y. X - to użytkownik gier przeglądarkowych, Y - może być podmiotem indywidualnym lub zbiorowym, politykiem lub zelotą absurdów i nadużyć władzy, kimś, kto staje się jednak "podsądnym” dyskursu nacechowanego ironią (w książce dużo jest mowy o metaforze, o jej technologii działania i o oddziaływaniu, brakuje zaś uwag o ironii, o metonimii, o hiperboli, które w perspektywie gier przeglądarkowych również modelują emancypacyjny dyskurs obywatelski), a konstruowanego na podstawie metafor (autor monografii opisuje m.in. „anomiczne obrazy procesów politycznych w grach metaforach objaśniających” oraz „atroficzne obrazy zachowań aktorów politycznych w grach metaforach ekspresywnych" - por. rozdział 4.). Pod pozorną oczywistością powyższej zasady ukrywa się jednak ważna groznawcza hipoteza: dla wielu użytkowników gry przeglądarkowe pełnią głównie funkcje ludyczne, są technologiami rozrywki, dla innych są medium, poprzez które mogą oni wyładować frustracje, eksponować własne nastawienie wobec różnych spraw, wreszcie służą artykulacji konkretnych postaw politycznych.

Monografia składa się z czterech rozdziałów, z zakończenia, bogatej bibliografii, wykazu rysunków, tabel i zrzutów ekranu, z załączników (w tym załącznika 1a będącego listą gier metafor objaśniających oraz załącznika $1 \mathrm{~b}$ będącego listą gier metafor ekspresywnych), indeksu nazwisk oraz użytecznego słownika terminów. Wszystkie te elementy tworzą spójną strukturę wzbogaconą o angielskie tłumaczenia spisu treści, wprowadzenia oraz zakończenia. Podaję te szczegóły, aby pokazać, że monografia jest całością, w której myślenie metaforyczne, formując dyskurs polityczny zapośredniczony medialnie, społecznie i kulturowo, odzwierciedla granice działań komunikacyjnych użytkowników Internetu.

Autor recenzowanej monografii porządkuje historycznie, kulturowo i technologicznie rozwój gier przeglądarkowych w Polsce na tle przemysłu growego i dyskursów polityczno-kulturowych istniejących w innych krajach, głównie w USA. Ta monografia jest ważna dla historyków gier, a szerzej dla groznawców właśnie dlatego, że Babecki uwzględnił wiele faktów z przeszłości funkcjonowania gier w ogóle, w tym komputerowych, pośród nich zaś skoncentrował się na grach przeglądarkowych. Ciekawie, choć być może - dla osób zajmujących się zależnościami między technologiami i różnego rodzaju tekstami kultury - nieoryginalnie, ale za to rzeczowo i systematycznie omówił w książce wiele istotnych teorii literaturoznawczych, medioznawczych i kulturoznawczych. Babecki jest czujny metodologicznie, a przywołane przez niego liczne koncepcje nie zostały zredukowane do erudycyjnych ornamentów, nie są więc 
autoteliczne, zostały one bowiem opisowo i interpretacyjnie sfunkcjonalizowane. Na odpowiednim poziomie uogólnienia nawet metafory w rozumieniu Babeckiego stają się „technologiami” działania politycznego.

Autor monografii Metaforyka polskich gier przegladarkowych pokazuje, iż to, co wydawałoby się, że istnieje wyłącznie na marginesach dyskursów publicznych - mowa o grach przeglądarkowych ${ }^{1}$, a więc grach, do uruchomienia których konieczna jest przeglądarka internetowa, ma wpływ, obrazując emocje i różnorodne postawy użytkowników odnoszących się przy ich wykorzystaniu do różnych ludzi i wydarzeń, na komunikowanie społeczne. Babecki wielokrotnie udowadnia, że Internet nie lubi marginesów, że jest siecią dynamiczną; przecież to, co nie istnieje w centrach dyskursów konstruowanych przez media tradycyjne (telewizja, prasa, radio), wcale nie musi być nieistotne dla osób korzystających z mediów digitalnych w tym z Internetu. Każdy badacz Sieci wie, że dyskursy konstruuje się w niej według modelu bottom-up, a więc to pojedynczy użytkownicy znajdują dla siebie platformę, na której mogą i potrafią komentować, tworzyć i stymulować różnego rodzaju trendy, reakcje czy dyskusje. Przynajmniej od czasów Andrew Keena² wiemy, że komunikacja XXI wieku to komunikacja tworzona przez amatorów, oddolnie, choć i na nią można wpływać za pomocą konkretnych narzędzi monitorujących i symulujących działania komunikacyjne. Ale tak, Babecki ma rację, bo gry przeglądarkowe, choć pełnią różne funkcje, były i są mediami społecznej aktywności.

Pragnę jednak zauważyć, że nad powierzchnią treści recenzowanej monografii unosi się delikatna mgła melancholii. Oczywiście, że taki efekt nie jest zamierzony przez Babeckiego, lecz raczej stanowi konsekwencję lektury poczynionej przez piszącego te słowa. Melancholia uświadamia coś niezwykle ważnego. Autor Metaforyki polskich gier przeglądarkowych pisze, że właściwie udało mu się zebrać i przebadać 46 gier przeglądarkowych, gdyż wiele innych, do których nie mógł dotrzeć, zniknęło wcześniej z Internetu. Melancholia recenzenta jest reakcją na tymczasowość zjawisk i treści opisanych przez autora monografii, która tym bardziej staje się potrzebnym, choć osobliwym raportem ze zdarzeń ważnych, ulotnych jak bicie internetowego serca, mających przecież wpływ na wyobrażenia społeczne zarówno digital immigrants (do których zalicza się recenzent), jak i digital natives (ci użytkownicy, dla których otoczenie sieciowe, cyfrowe, konwergentne, audiowizualne jest naturalnym, pierwszym otoczeniem medialnym) ${ }^{3}$. Wynika również z tego, iż po ponad piętnastu latach badania komunikacji w Internecie recenzent uświada-

\footnotetext{
${ }^{1}$ Gry przeglądarkowe są odmianą gier cyfrowych, do korzystania z nich niezbędne są przeglądarki internetowe, najczęściej nie trzeba ich pobierać na dysk komputera. Adobe Flash Player lub Java są aplikacjami wymaganymi przy korzystaniu z tego rodzaju gier. Por. Miłosz Babecki, Metaforyka polskich gier przeglądarkowych. Konteksty - porównania - analizy. Olsztyn: Wydawnictwo Uniwersytetu WarmińskoMazurskiego w Olsztynie, 2020, 335.

${ }^{2}$ Andrew Keen, Kult amatora. Jak internet niszczy kulture, tłum. M. Bernatowicz, K. Topolska-Ghariani. Warszawa: Wydawnictwa Akademickie i Profesjonalne, 2007.

${ }^{3}$ Digital natives oraz digital immigrants to pojęcia wprowadzone przez Marca Prensky'ego. Traktuję je metaforycznie, zachowując jednak ich źródłowy sens. Uczestnik kultury charakteryzowany jako digital native (DN) posługuje się technologami cyfrowymi od samego początku swojego społecznego, medialnie zapośredniczonego, rozwoju. Digital immigrant (DI) to podmiot, który uczy się nowych "gramatyk”, „słowników” i „sytuacji”, gdyż komunikacyjnie „rozwijał się” jeszcze w czasie, gdy dominowały media analogowe. Przyjmuję, że dla DI dominującym medium było medium książki drukowanej, a dyskurs był zdeterminowany logocentrycznie, dla DN zaś dominującym medium są media audiowizualne cyfrowe, a dyskurs jest zdeterminowany okulocentrycznie i interaktywnie. Por. Marc Prensky, Digital Natives, Digital Immigrants, dostęp: 18.07.2021, http://www.marcprensky.com/writing/Prensky-Digital Natives, Digital Immigrants-Part1.pdf.
} 
mia sobie, jak wielu badaczy przeminęło, choć na ich miejsce pojawili się następni; jak niektóre koncepcje się zdezaktualizowały, a inne wciąż są źródłem twórczych interpretacji i opisów. Duża w tym dynamika, rzeczywista różnorodność. Ulotne są do pewnego stopnia nie tylko treści internetowe, ale i rezultaty badań odnoszących się do różnych zjawisk komunikacyjnych w Sieci. Dla metateoretyka komunikacji cyfrowej, w tym gier, za którego uważa się recenzent, cenne jest to, co świadczy jak najlepiej o autorze Metaforyki..., a mianowicie syntetyczne przedstawienie przeglądarkowych gier metafor na tle uwarunkowanych technologicznie, komunikacyjnie, kulturowo i politycznie zjawisk. Granicę między melancholią a tymczasowością wyznacza „poetyka" archiwum, w którą wpisuje się recenzowana monografia. Dla badaczy gier cyfrowych i dla politologów monografia Babeckiego stanie się źródłem wiedzy o unikatowych, nie do odtworzenia w czasie rzeczywistym sytuacjach, działaniach i tekstach kultury, które odzwierciedlały dynamikę tej wciąż niepewnej siebie i porywczej polskiej demokracji.

Miłosz Babecki sięga między innymi po „klasyków” komunikacji digitalnej (dziś rzadziej, niestety, już cytowanych): Sherry Turkle ${ }^{4}$ i Geerta Lovinka ${ }^{5}$, korzysta z różnych koncepcji w badaniach nad metaforą George'a Lakoffa i Marka Johnsona (w tym zakresie nic nowego nie wnoszą uwagi autora recenzowanej monografii, jednak przywołana teoria została przez niego dobrze sfunkcjonalizowana) czy Teresy Dobrzyńskiej, korzysta z prac tekstologicznych Anny Duszak oraz badań z obszaru komunikacji społecznej Bogusławy Dobek-Ostrowskiej. Przekonuje mnie ta misterna - choć lepsze byłoby słowo „interdyscyplinarna” - perspektywa badawcza, gdyż autor Metaforyki... nawet na metapoziomie pokazuje czytelnikowi, że gry przeglądarkowe są istotne i należy je opisywać przy wykorzystaniu wszystkich możliwych narzędzi badawczych. Tak, tak się bada to, co cyfrowe. Ulotność przekazów i treści nie zwalnia uczonego $\mathrm{z}$ tego, by się nimi zajmował z powagą i otwartością na zmianę, na którą zawsze szybciej reagują użytkownicy niż badacze, choć to namysł uczonych jest poznawczo trwalszy. Wciąż Achilles i żółw chcą coś sobie udowodnić (żaden z elementów tej metafory nie jest nacechowany negatywnie). Trudno bowiem pisać prace naukowe w tradycyjnym stylu na temat tak zmiennej rzeczywistości, jak rzeczywistość digitalnie zapośredniczonej komunikacji międzyludzkiej. Dlatego Babecki uruchamia wiele teorii, co jest i użyteczne, i redundantne. Użyteczne, bo pokazuje zmienność sytuacji i potrzebę nieustannego ich monitorowania. Redundantne, gdyż nagromadzenie licznych teorii utrudnia płynną lekturę całości. Bez wątpienia autor recenzowanej monografii jest znawcą tematu, więc wszelkie momenty lekturowego dubito w moim przypadku znikały z powodu jego rzeczowego i konsekwentnego wywodu. Celowo nie odnoszę się do ustaleń autora recenzowanej monografii dotyczących wydarzeń politycznych i osób będących ich podmiotami, do konkretnych gier i ich interpretacji, gdyż każdy

\footnotetext{
${ }^{4}$ Sherry Turkle jest niestety w polskich badaniach nad komunikowaniem zapośredniczonym cyfrowo wciąż zbyt mało obecna (jeśli dobrze pamiętam, to właśnie Maryla Hopfinger w książce Literatura i media. Po 1989 roku [Warszawa 2010] odnosi się do badań amerykańskiej uczonej), choć jej prace już teraz należy traktować jako tzw. pozycje klasyczne, dlatego doceniam przywoływanie badań tej uczonej w monografii przez Miłosza Babeckiego. Pozwolę sobie jednak na przypomnienie dwóch, niezwykle ważnych w badaniach nad Internetem i komunikacją digitalną prac: Life on the screen. Identity in the Age of the Internet (London: Weidenfeld \& Nicholson, 1996) oraz The Second Self. Computers and the Human Spirit (Cambridge: MIT Press, 2005).

${ }^{5}$ Miłosz Babecki przywołuje badania Geerta Lovinka, doceniam to, ale podaje adres do jego, napisanego wspólnie z D. Garcią, artykułu, co wynika z porząaku zaproponowanego wywodu, to oczywiste, choć warto pamiętać, że do - w dobrym rozumieniu - „kanonicznych” prac Geerta Lovinka zaliczamy m.in.: Dark Fiber. Tracking Critical Internet Culture (Cambridge: MIT Press, 2002) oraz Uncanny Networks: Dialogues with the Virtual Intelligentsia (Cambridge: MIT Press, 2002).
} 
czytelnik powinien (proszę traktować to wyrażenie nie tyle jako imperatyw, ile jako sugestię) w tym zakresie zapoznać się z grami, przypomnieć sobie odpowiednie konteksty, a następnie - wypracować własny ogląd sytuacji.

Recenzje mają to do siebie, że musi się w nich znaleźć element krytyczny. Nie usprawiedliwiam się w tym miejscu, lecz jedynie pragnę pokazać, że doceniam ogrom wykonanej przez Babeckiego pracy. Stworzył on dzieło ciekawe i potrzebne, jak pisałem powyżej, jednak czułem niedosyt w kilku obszarach.

Autor monografii nie uwzględnił specyfiki Internetu, gdyż koncentrując się na grach przeglądarkowych, zredukował w swych dociekaniach fakt, iż funkcjonują one w niezwykle płynnej, bezskalowej sieci ${ }^{6}$. Brakło mi odniesień do teorii wyobrażeń społecznych oraz do interakcjonizmu symbolicznego Herberta Blumera, kolejnego „klasyka”, gdyż gry przeglądarkowe można by omówić, korzystając z koncepcji zaproponowanej przez tego uczonego (zdaję sobie sprawę, że wcześniej pisałem o „nadmiarze” teorii, a obecnie przykładowo sugeruję te koncepcje, których mi brakuje. Czynię tak z jednego zasadniczego powodu, otóż niektóre spostrzeżenia autora mogłyby - przy wykorzystaniu określonych ujęć badawczych, jak wyżej wspomniane, skrócić w niektórych miejscach wywód, a jednocześnie dobrze wzmocnić intrygujące poznawczo ustalenia autora. Wyobraźmy sobie, jak interakcjonizm symboliczny przydałby się w rozważaniach Babeckiego na temat znaczenia i funkcji ramy pierwotnej i ram problemowych [por. rozdział 2.]). Wspominam o Blumerze, znów klasyku, gdyż w moim przekonaniu Babecki, choć korzysta z refleksji strukturalistycznej i hermeneutycznej, traktując je „nieortodoksyjnie” (oczywiście nie tylko te tradycje można by rekonstruować w jego rozprawie, jednak i terminologia [interpretacja, rozumienie, sens, znaczenie], i badacze - czy to de Saussure, czy Heidegger - pozwalają rozpoznać taki właśnie metodologiczny „trop”7), to koncentrując się na funkcji odbiorcy/ użytkownika/gracza - zmierza w stronę pragmatyzmu, co jest oczywiście zasadne.

Gry przeglądarkowe są ciekawymi mediami, za pomocą których tworzy się, rozprzestrzenia i utrwala wypowiedzi (złożone na poziomie kodów komunikacji) potoczne odzwierciedlające myślenie zdroworozsądkowe (ang. common sense). Czuję niedosyt dociekań odnoszących się do "granic” racjonalności użytkowników. Oczywiście autor ma świadomość zjawisk, które bliskie są badaniom nad myśleniem i mówieniem potocznym, jednak gry przeglądarkowe jako technologie dyskursywne służą potwierdzeniu hipotezy, według której każdy użytkownik może kontestować rzeczywistość polityczną, grając online i sytuować się w roli eksperta rozumiejącego wszystkie zawiłości świata, korzystającego z dostępnej i dającej się łatwo, niemetodycznie przyswoić „oczywistej” i „naturalnej” wiedzy. Wystarczy, że Clifford Geertz przemówi: „Myśl potoczna, podobnie jak Król Lear, Nowy Testament i mechanika kwantowa składa się z opisów rzekomo trafiających w sedno spraw"8.

\footnotetext{
${ }^{6}$ Więcej na ten temat można przeczytać w następujących monografiach: Albert-László Barabási, Linked. The New Science of Networks (Cambridge: Perseus Books Group, 2002) czy Duncan J. Watts, Six Degrees. The Science of a Connected Age (New York: Norton, 2003).

${ }^{7}$ W przypisach oraz w bibliografii znajdujemy konkretne adresy. W tytule jednego z podrozdziałów pojawia się nawet pojęcie „(de)konstrukcji”, choć myślę, że autor recenzowanej rozprawy traktuje to pojęcie raczej jako metaforę poznawczą.

${ }^{8}$ Clifford Geertz, Wiedza lokalna. Dalsze eseje z zakresu antropologii interpretatywnej, tłum. D. Wolska. Kraków: Wydawnictwo Uniwersytetu Jagiellońskiego, 2005, 91.
} 
W podsumowaniu pragnę wyraźnie podkreślić, iż monografia Babeckiego to dzieło przemyślane, spójne, oryginalne. Najważniejsza zaś hipoteza, mówiąca, że „metafory zawarte w grach przeglądarkowych są dla użytkownika widoczne i komunikatywne" (s. 23), została odpowiednio uargumentowana, podobnie z pozostałymi kluczowymi hipotezami badawczymi.

Pojawiające się powtórzenia czy nieścisłość w ułożeniu stron (między strony 294 i 295 wklejona jest kartka zawierająca strony 297 i 298) w wydruku nie mają wpływu na zawartość merytoryczną monografii.

Na marginesie dodam: dobrze, że jeszcze możemy czytać prace naukowe, w których pojęcie „hipotezy" jest nie tyle metaforą, ile "gatunkiem” wypowiedzi naukowej, z którym jej autor musi się zmierzyć, poszukując najlepszych, intersubiektywnie komunikowalnych argumentów.

\section{Bibliografia}

Babecki, Miłosz. Metaforyka polskich gier przegladarkowych. Konteksty - porównania analizy. Olsztyn: Wydawnictwo Uniwersytetu Warmińsko-Mazurskiego w Olsztynie, 2020.

Barabási, Albert-László. Linked. The New Science of Networks, Cambridge: Perseus Books Group, 2002.

Geertz, Clifford. Wiedza lokalna. Dalsze eseje z zakresu antropologii interpretatywnej, tłum. D. Wolska. Kraków: Wydawnictwo Uniwersytetu Jagiellońskiego, 2005.

Keen, Andrew. Kult amatora. Jak internet niszczy kulture, tłum. M. Bernatowicz, K. Topolska-Ghariani. Warszawa: Wydawnictwa Akademickie i Profesjonalne, 2007.

Lovink, Geert. Dark Fiber. Tracking Critical Internet Culture. Cambridge: MIT Press, 2002.
- - -. Uncanny Networks: Dialogues with the Virtual Intelligentsia. Cambridge: MIT Press, 2002.

Prensky, Marc. Digital Natives, Digital Immigrants. Dostęp 18.07.2021. http://www. marcprensky.com/writing/Prensky-Digital Natives, Digital Immigrants-Part1.pdf.

Turkle, Sherry. Life on the screen. Identity in the Age of the Internet. London: Weidenfeld \& Nicholson, 1996.

- - -. The Second Self. Computers and the Human Spirit. Cambridge: MIT Press, 2005.

Watts, Duncan J. Six Degrees. The Science of a Connected Age. New York: Norton 2003. 


\title{
SEOWA KLUCZOWE:
}

\author{
I N T E R N E T
}

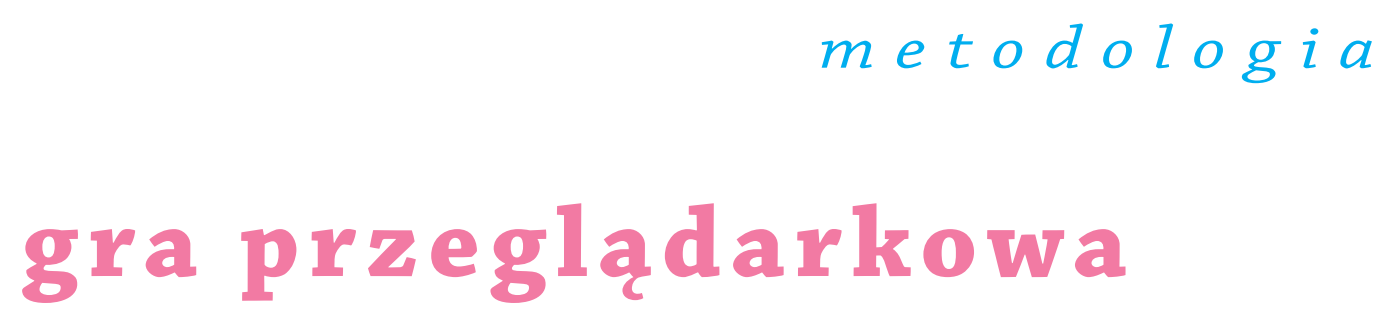

\begin{abstract}
Abstrakt:
Recenzja monografii Miłosza Babeckiego zatytułowanej Metaforyka polskich gier przegladarkowych. Konteksty - porównania - analizy (Wydawnictwo Uniwersytetu Warmińsko-Mazurskiego w Olsztynie, Olsztyn 2020, ss. 340) zawiera uwagi pozytywne na temat teoretycznych podstaw dzieła, a także na temat ciekawych interpretacji. Autor recenzji zauważa, że Miłosz Babecki mógł poświęcić więcej miejsca w swej monografii na aspekty sieciowe istotne w przypadku funkcjonowania gier przeglądarkowych (i nie tylko). W konkluzji autor recenzji rekomenduje czytelnikom lekturę monografii.
\end{abstract}




\section{teoria}

komunikacja

\section{NOTA O AUTORZE:}

Marek Kaźmierczak - zatrudniony w Instytucie Filmu, Mediów i Sztuk Audiowizualnych WFPiK UAM. Jest nieortodoksyjnym semiotykiem. Prowadzi badania w obszarze komparatystyki transmedialnej, ekokrytycyzmu w kulturze audiowizualnej oraz relacji między myśleniem potocznym i kulturą popularną. Publikował w następujących czasopismach: „Images”, „Teksty Drugie”, „Pamiętnik Literacki”, „Przestrzenie Teorii”, „Przegląd Humanistyczny”, „Politeja”, „The Journal of Contemporary Central and Eastern Europe”. 